\title{
Outdoor Performance of Micro Scale Wind Turbine Stand alone System
}

\author{
Ahmed. A. Hossam-Eldin, Karim H. Youssef, and Kareem M. AboRas
}

\begin{abstract}
Recent current rapid industrial development and energy shortage are essential problems, which face most of the developing countries. Moreover, increased prices of fossil fuel and advanced energy conversion technology lead to the need for renewable energy resources. A study, modelling and simulation of an outdoor micro scale stand alone wind turbine was carried out. For model validation an experimental study was applied. In this research the aim was to clarify effects of real outdoor operating conditions and the instantaneous fluctuations of both wind direction and wind speed on the actual produced power. The results were compared with manufacturer's data. The experiments were carried out in Borg Al-Arab, Alexandria. This location is on the north Western Coast of Alexandria. The results showed a real max output power for outdoor micro scale wind turbine, which is different from manufacturer's value. This is due to the fact that the direction of wind speed is not the same as that of the manufacturer's data. The measured wind speed and direction by the portable metrological weather station anemometer varied with time. The blade tail response could not change the blade direction at the same instant of the wind direction variation. Therefore, designers and users of micro scale wind turbine stand alone system cannot rely on the maker's name plate data to reach the required power.
\end{abstract}

Index Terms-Micro-turbine, wind turbine, inverters, renewable energy and hybrid system.

\section{INTRODUCTION}

Pollution and depletion of fossil fuels for electrical power generation are main factors to use renewable energy. Wind energy conversion system is becoming a most popular system all over the world. It gets emission-free, clean and green electrical power generation. The first wind turbo generator was built on 1888 in USA. It was very inefficient,producing $12 \mathrm{~kW}$ only. The wind energy industry has experienced a growth of about 30 percent each year through the last decade [1].

Wind turbines has two operation modes fixed speed and variable speed, the generator is directly connected to the grid or load for a fixed speed wind turbine while it is controlled by power electronic devices to convert variable frequency and variable voltage power into constant frequency and constant voltage for a variable speed wind turbine.

Nowadays there are two generators types used in large scale WECS to convert the wind power into electrical power which are Permanent magnet synchronous generator (PMSG) and doubly fed induction generator (DFIG). PMSG is a direct

Manuscript received November 9, 2015; revised March 3, 2016.

The authors are with Alexandria University, Egypt (e-mail: a.hossamudn44@gmail.com,

Kareem_aboras@yahoo.com). drive type generator, consequently it does not require excitation current and gear box, thus PMSG shows a great performance in WECS [2]. WECS with PMSG can obviate the wear and tear of gear problem, it can aid wind turbine to operate more with reduce maintenance and reliable [3]. WECS can be used in two different ways with respect to the load side: grid connected system and isolated standalone system. Grid connected system increased diversification of energy sources, robustness, voltage support, energy efficiency, reduced distribution and transmission losses and reliability of the system. Standalone systems are satisfied the needs of small scale industries for rural areas, it uses for systems are located at remote areas.

\section{Wind TURBINE CHARACTERISTICS, MATHEMATICAL MODEL AND SIMULATION}

The mechanical power on the rotor can be calculated as function of wind speed:

$$
P_{R}=c_{p} \frac{1}{2} \rho A v_{w}^{3}
$$

And the output electrical power is equal to

$$
P_{e}=P_{R} \times \eta_{m} \times \eta_{G}
$$

where: $A=$ swept area of the rotor $\left(\mathrm{m}^{2}\right), v_{w}=$ wind velocity $(\mathrm{m} / \mathrm{s}), c_{p}=$ rotor power coefficient, $\rho=$ air density $\left(\mathrm{kg} / \mathrm{m}^{3}\right), P_{R}$ $=$ rotor power $(\mathrm{W}), \eta_{m}=$ mechanical efficiency and $\eta_{G}=$ generator efficiency.

The $c_{p}$ factor is depending on the tip speed ratio $\lambda$ and pitch angle $\beta$ [4].

$$
\begin{gathered}
c_{p}(\lambda \beta)=c_{1}\left(c_{2} \frac{1}{\lambda_{i}}-c_{3} \beta-c_{4} \beta^{x}-c_{5}\right) e^{-c_{6} \frac{1}{\lambda_{i}}} \\
\frac{1}{\lambda_{i}}=\frac{1}{\lambda+0.08 \beta}-\frac{0.035}{1+\beta^{3}}
\end{gathered}
$$

where: $c_{1}=0.5176, c_{2}=116, c_{3}=0.4, c_{4}=5, c_{5}=21, c_{6}=$ 0.0068 .

First the wind turbine model was based on real value system. Second, the fixed pitch turbine model was made to represent a controlled fixed pitch turbine. The pitch control was achieved through hydraulic manipulation. A new power coefficient equation was derived using a fixed pitch angle turbine $(\beta=0)$ as [5], [6]: 


$$
c_{p}(\lambda)=0.5176\left(\frac{116}{\lambda}-9.06\right) e^{\frac{-z 1}{\lambda}+0.735}+0.0068 \lambda
$$

The power and torque characteristics of the wind turbine are represented by equations (6) and (7).

$$
P_{m}=0.5 \rho A\left(0.5176\left(\frac{116}{\lambda}-9.06\right) e^{\frac{-z 1}{\lambda}+0.735}+0.0068 \lambda\right) v_{w}^{3}
$$

And, the torque is:

$$
T_{m}=0.5 \rho A\left(0.5176\left(\frac{116}{\lambda}-9.06\right) e^{\frac{-z 1}{\lambda}+0.735}+0.0068 \lambda\right) v_{w}^{3} \frac{R}{c \lambda v_{w}}(7)
$$

The output torque and the generator rotor speed are given by Eq. (8) [7].

$$
T_{m}=J_{s} \frac{d \omega}{d t}
$$

where: $T_{m}=$ mechanical torque, $J_{s}=$ total inertia of windturbine and $\omega=$ is angular velocity of the turbine shaft.

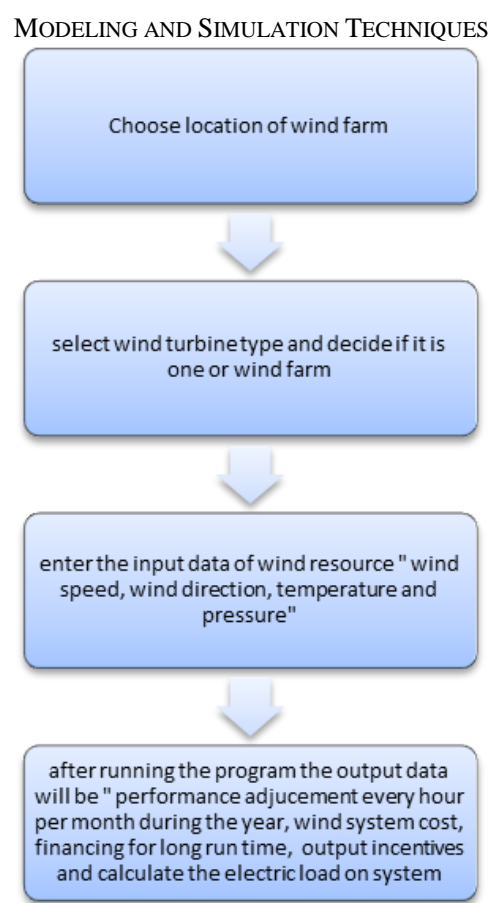

A modified "System advisor model" (SAM) program was adopted to get performance predictions and cost of energy estimates for power projects based on installation, operating costs and system design parameters, specified as inputs to the model. SAM assumes that the renewable energy system delivers power either to an electric grid, or to a grid-connected building or facility to meet electric load. Creating a SAM file involves choosing both a performance model and a financial model to represent the project. SAM automatically populates input variables with a set of default values. The input is modified to provide information about the project location, the type of equipment in the system, the cost of installing and operating the system, and financial and incentives assumptions. Then the simulation program is run to get the simulated results. It has to be noted that if verifies the output of data maker it gives an indication of confidence. Same temperature, pressure, wind direction and wind speed conditions were applied as input. The program used is shown in Fig. 1.

The modified SAM consists of a user interface, calculation engine, and programming interface. The user interface provides access to input variables and simulation controls and displays tables and graphs of results. The user interface performs three basic functions:

- Provide access to input variables. The input variables describe the physical characteristics of a system, and the cost and financial assumptions for a project.

- A basic simulation, or more advanced simulations for optimization and sensitivity studies, can be performed.

- Provide access to output variables in tables and /or graphs on the results page.

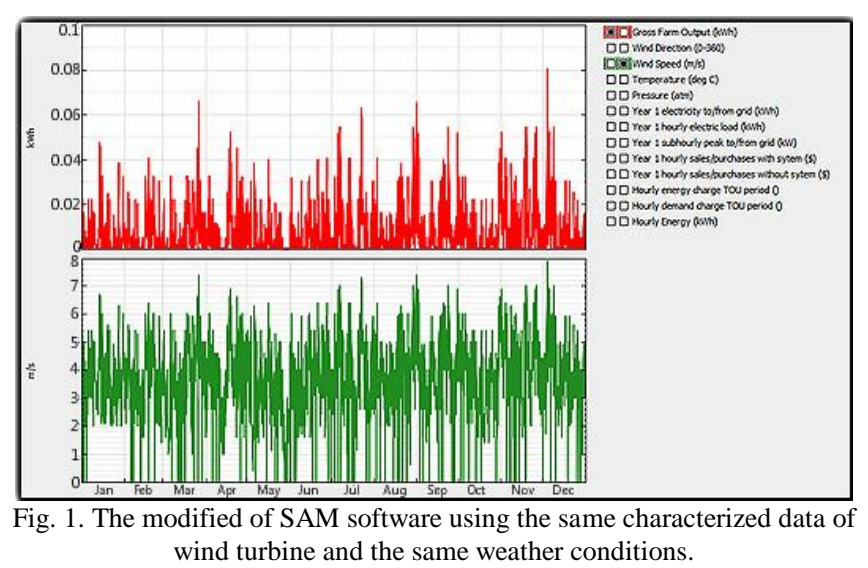

The SAM Simulation Core (SSC), performs a time-step-by time-step simulation of a power system performance, and calculates project cash flow and financial metrics annually. The programming interface allows external programs to interact with SAM [8].

\section{EXPERIMENTAL WORK}

A small module wind turbine Z-501 made by Zephyr, Japan was used. The wind turbine is a part of a hybrid system.It consists of a solar panel with a controller and an inverter. Itis illustrated in Fig. 2(a and b), (a) the hybrid system between the Zypher wind turbine Z-501 and two panels of solar cell SF80-A. (b) A portable metrological weather station is attached with the wind turbine with the controller and the data logger devices.

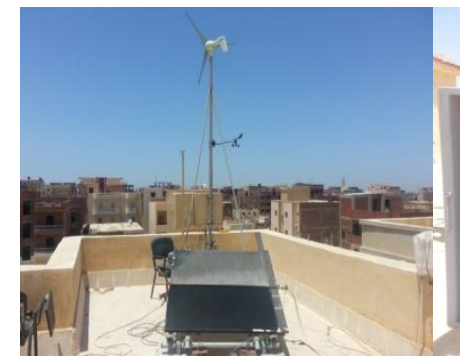

(a)

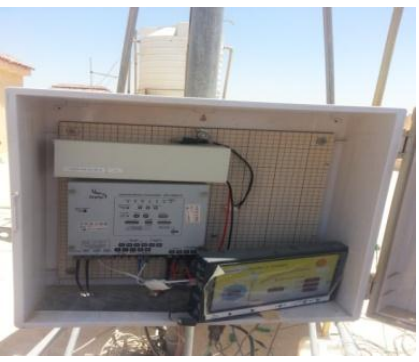

(b)
Fig. 2. The experimental installation. 
The wind turbine generator has the following specifications as shown in Table I.

TABLE I: MODULE SPECIFICATIONS [9]

\begin{tabular}{|l|l|}
\hline \multicolumn{2}{|c|}{ General configuration } \\
\hline Rotation operating range diameter & $1240 \mathrm{~mm}$. \\
\hline Weight & $6 \mathrm{~kg}$. \\
\hline Main body length & $675 \mathrm{~mm}$. \\
\hline Start of power generation (cut-in) wind speed & $2.5 \mathrm{~m} / \mathrm{s}$ \\
\hline Cut-in rotational speed & $500 \mathrm{rpm}$. \\
\hline Rated output speed & $1700 \mathrm{rpm}$. \\
\hline Upper limit voltage adjustment range & $\begin{array}{l}\text { DC13.0 } \\
17.0 \mathrm{~V} .\end{array}$ \\
\hline $\begin{array}{l}\text { Rated output (rated wind speed } 12.5 \mathrm{~m} / \mathrm{s} \text { at the } \\
\text { time) }\end{array}$ & $400 \mathrm{~W}$. \\
\hline Maximum output & $450 \mathrm{~W}$. \\
\hline Rated output voltage & $\mathrm{DC} 12 \mathrm{~V}$. \\
\hline Battery bank voltage $\left(V_{d z}\right)$ & $12 \mathrm{~V}$. \\
\hline Number of blades & 3. \\
\hline Gear ratio & $1 / 1$. \\
\hline Pitch angle & $0^{\circ}$ \\
\hline
\end{tabular}

Battery model is The Lifeline GPL-27T is a high performance, Mil-Spec, AGM battery. It has an industry leading $2 \%$ per month self discharge rate at $\left(25^{\circ} \mathrm{C}\right)$. No sulfuric acid leaks, no acid clean up and more power in the same space when compared to conventional batteries. The GPL-27T is designed for a charging current up to $250 \mathrm{~A}$ or $250 \%$ of the rated Amp Hour Capacity due to low battery internal resistance, its Nominal voltage s $12 \mathrm{~V}$ and Ampere hour capacity at $20 \mathrm{hr}$ rates $100 \mathrm{~A}$ [10].

The controller CP-1000 is a controller for a wind turbine (Z-501) power optimally to start, run and brake the wind turbine. In addition, an emergency button is provided that can also stop manually the wind turbineas shown in Fig. 3. Its characteristics are given as:

Input:

- Rated input voltage is $12 \mathrm{~V}$ and wind generation maximum input power is $500 \mathrm{~W}$.

Output:

- Load output voltage is from battery voltage and maximum output current $5 \mathrm{~A}$.

Communication input:

- RM-1000 for RS-485 (with terminator ON / OFF) and RS-232C for PC (for maintenance).

Its Functions are:

- Battery over-discharge protection.

- Day and night detection.

- Anemometer connection.

- Temperature sensor connection.

- Load output timer.

- Forced load output.

- Wind turbine stop as an emergency.

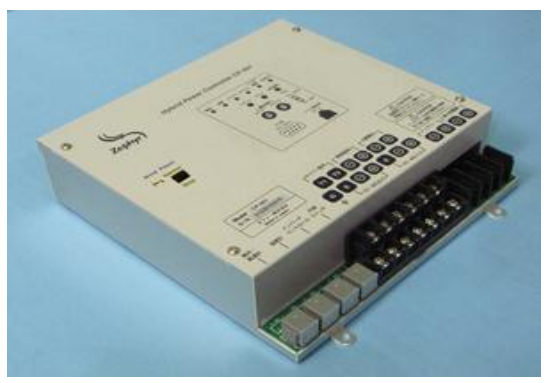

Fig. 3. Hyper controller CP-1000 [11].
The inverter HS-250 has characteristics shown in Table II, flexible response to changes in the battery voltage, such as tough response at the time of peak output, making it ideal for cases that require high reliability.

TABLE II: High PRECISION SINE WAVE INVERTER [11]

\begin{tabular}{|c|c|c|}
\hline Type & & HS-250 \\
\hline Input dc voltage & & $12 \mathrm{~V}$ \\
\hline \multirow{2}{*}{ Output } & Surge & $400 \mathrm{~W}$ \\
\hline & Continuous & $250 \mathrm{~W}$ \\
\hline \multicolumn{2}{|l|}{ Output voltage } & 100 Vrms $-3 \%+5 \%$ \\
\hline \multicolumn{2}{|c|}{ Output fluctuation width } & $\pm 1 \%$ \\
\hline \multicolumn{2}{|l|}{ Output waveform } & Sine wave \\
\hline \multicolumn{2}{|l|}{ Output frequency } & $50 \mathrm{~Hz}$ or $60 \mathrm{~Hz}(1 \%)$ \\
\hline \multicolumn{2}{|c|}{ Conversion efficiency } & About $90 \%$ (maximum) \\
\hline \multicolumn{2}{|c|}{ DC rated input voltage } & $12 \mathrm{~V}$ \\
\hline \multicolumn{2}{|l|}{ Input voltage } & $11 \rightarrow 15 \mathrm{VDC}$ \\
\hline \multicolumn{2}{|l|}{ Low voltage alarm } & $11 \mathrm{~V}$ \\
\hline \multicolumn{2}{|c|}{ Low voltage cut-off } & $10.7 \mathrm{~V}$ \\
\hline \multicolumn{2}{|l|}{ No-load power } & $4 \mathrm{~W}$ \\
\hline \multicolumn{2}{|l|}{ Storage humidity } & $90 \%$ or less \\
\hline
\end{tabular}

The data logger device is a Remote Monitor RM-1000 (wireless LAN)a multi-function remote control devices that are developed for the Zephyr wind power generator, made in Japan. It receive output voltage from the wind turbine, instantaneous output power, wind direction, wind speed, pressure and air temperature from the portable metrological weather station attached with wind turbine.

The experimental work on the wind turbine continued for four months. Maximum wind speed during that time was 9 $\mathrm{m} / \mathrm{s}$. Temperature, humidity, pressure and the wind speed were measured using the metrological weather station. The data was instantaneously recorded every second. The average value was reported each 15 minutes on an LCD of the data logger.

\section{EXPERIMENT RESULTS AND DISCUSSIONS}

The results were registered for 5 times at each point. The average values of the output power and wind speed were reported. The results were recorded and the relations were discussed.

The instantaneous experimental measured output power and speed of wind turbine during first 50 secondsis given in Fig. 4.

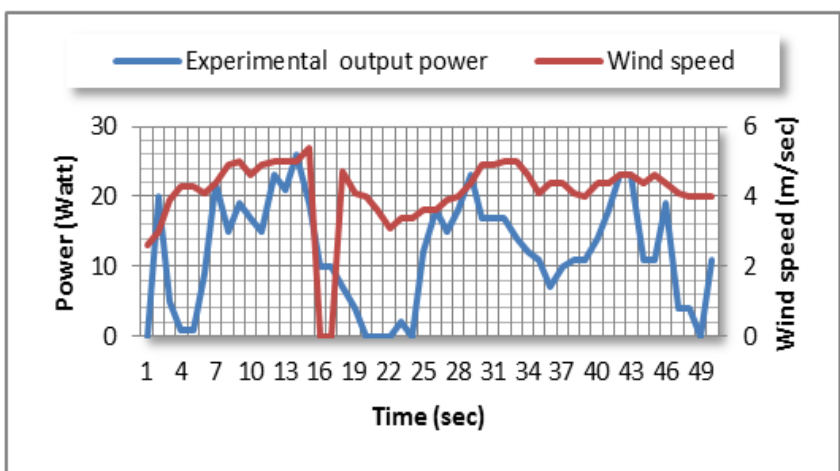

Fig. 4. Relation between the experimental output power and the wind speed during first 50 seconds. 
Fig. 4 shows the variation of the output power against the wind speed during the first $50 \mathrm{sec}$. It is clear that the power curve is not responding according to the change in wind speed. From the curves above, it is noticed that the peak speed is not at the peak output power and vice versa. There was a difference in measured values and that of data sheets as shown in Table III.

TABLE III: COMPARISON BETWEEN EXPERIMENTAL OUTPUT POWER AND OUTPUT POWER IN DATA SHEET AT CERTAIN WIND SPEED

\begin{tabular}{|c|c|c|c|}
\hline $\begin{array}{l}\text { wind } \\
\text { speed }\end{array}$ & measured power & power data sheet & $\begin{array}{c}\text { \%deviation } \\
\text { from nominal } \\
\text { power }\end{array}$ \\
\hline 2.6 & 0 & 1 & -0.25 \\
\hline 3 & 20 & 3.571 & 4.10725 \\
\hline 3.1 & 0 & 3.571 & -0.89275 \\
\hline 3.4 & 2 & 7.043 & -1.26075 \\
\hline 3.4 & 0 & 7.043 & -1.76075 \\
\hline 3.6 & 0 & 7.443 & -1.86075 \\
\hline 3.6 & 12 & 7.443 & 1.13925 \\
\hline 3.6 & 18 & 7.443 & 2.63925 \\
\hline 3.9 & 5 & 10.514 & -1.3785 \\
\hline 3.9 & 15 & 10.514 & 1.1215 \\
\hline 4 & 0 & 10.714 & -2.6785 \\
\hline 4 & 18 & 10.714 & 1.8215 \\
\hline 4 & 11 & 10.714 & 0.0715 \\
\hline 4 & 4 & 10.714 & -1.6785 \\
\hline 4.1 & 9 & 10.974 & -0.4935 \\
\hline 4.1 & 4 & 10.974 & -1.7435 \\
\hline 4.1 & 11 & 10.974 & 0.0065 \\
\hline 4.1 & 11 & 10.974 & 0.0065 \\
\hline 4.1 & 4 & 10.974 & -1.7435 \\
\hline 4.3 & 1 & 13.286 & -3.0715 \\
\hline 4.3 & 1 & 13.286 & -3.0715 \\
\hline 4.4 & 22 & 13.286 & 2.1785 \\
\hline 4.4 & 23 & 13.286 & 2.4285 \\
\hline 4.4 & 7 & 13.286 & -1.5715 \\
\hline 4.4 & 10 & 13.286 & -0.8215 \\
\hline 4.4 & 14 & 13.286 & 0.1785 \\
\hline 4.4 & 18 & 13.286 & 1.1785 \\
\hline 4.4 & 11 & 13.286 & -0.5715 \\
\hline 4.4 & 19 & 13.286 & 1.4285 \\
\hline 4.6 & 17 & 15.256 & 0.436 \\
\hline 4.6 & 12 & 15.256 & -0.814 \\
\hline 4.6 & 23 & 15.256 & 1.936 \\
\hline $\begin{array}{l}\text { wind } \\
\text { speed }\end{array}$ & measured power & power data sheet & $\begin{array}{c}\% \text { deviation } \\
\text { from nominal } \\
\text { power }\end{array}$ \\
\hline 4.6 & 23 & 15.256 & 1.936 \\
\hline 4.6 & 11 & 15.256 & -1.064 \\
\hline 4.7 & 7 & 16.256 & -2.314 \\
\hline 4.9 & 15 & 24.874 & -2.4685 \\
\hline 4.9 & 15 & 24.874 & -2.4685 \\
\hline 4.9 & 17 & 24.874 & -1.9685 \\
\hline 4.9 & 17 & 24.874 & -1.9685 \\
\hline 5 & 19 & 25 & -1.5 \\
\hline 5 & 23 & 25 & -0.5 \\
\hline 5 & 21 & 25 & -1 \\
\hline 5 & 26 & 25 & 0.25 \\
\hline 5 & 17 & 25 & -2 \\
\hline 5 & 14 & 25 & -2.75 \\
\hline 5.4 & 19 & 35.714 & -4.1785 \\
\hline
\end{tabular}

The reasons are attributed to:

The fact, that the turbine mechanical response to wind direction variation is too slow to sense that quick variation. This is because the blades take sensible time to move to the position where the wind is perpendicular on the blades. Therefore, the outdoor turbine output power is less than the indoor test turbine (which was taken in data sheet).
When the wind speed increases, the output wind power increases after few seconds. This illustrates the reason for shift. The blade tail response can't change the blade direction at the same time of wind direction change. The fan tail tried to change its direction to match the wind direction. The fan tail's time response was larger than the wind direction change time. The fan tail did not catch the perpendicular wind on the turbine blades.

The data was taken during two hours and fifty minutes in all day time. The wind changes its direction and magnitude for different instances with respect to $\mathrm{N}\left(23^{\circ}\right)$ as shown in Fig. 5.

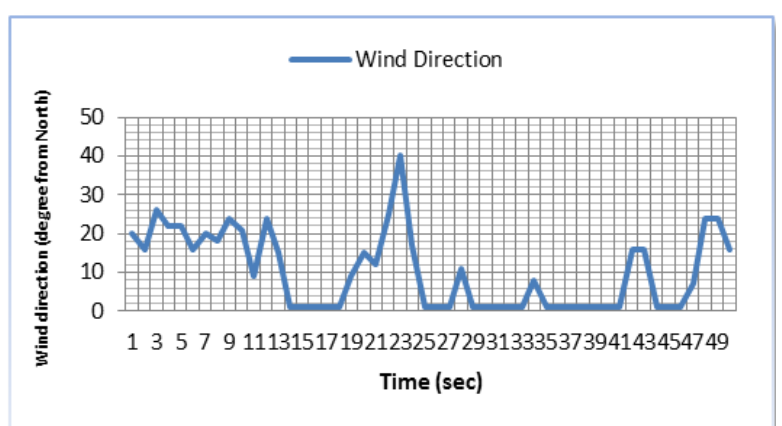

Fig. 5. Wind direction with north 23 degree during first 50 seconds.

Also, the ambient temperature and pressure during first 50 seconds through the experiment reading was as shown in Fig. 6 , there was not no huge variation in the value of pressure and temperature. Also, for all measurement readings there are no change in temperature and pressure values.

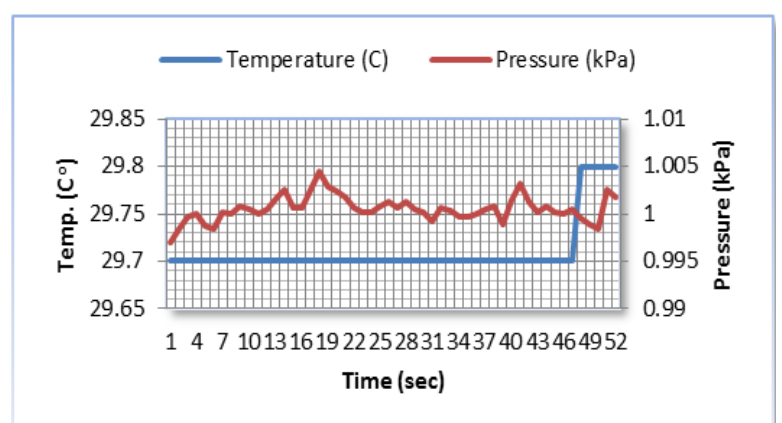

Fig. 6. Ambient condition for the temperatures and the pressures during the first 50 seconds.

The output voltage was measured as shown in Fig. 7. It indicates a variation of voltage with respect to time between $11.8 \mathrm{~V}$ and $12.1 \mathrm{~V}$ which when compared with the data sheets of the maker can be considered as constant at $12 \mathrm{~V}$ with relative error $\pm 1.667 \%$.

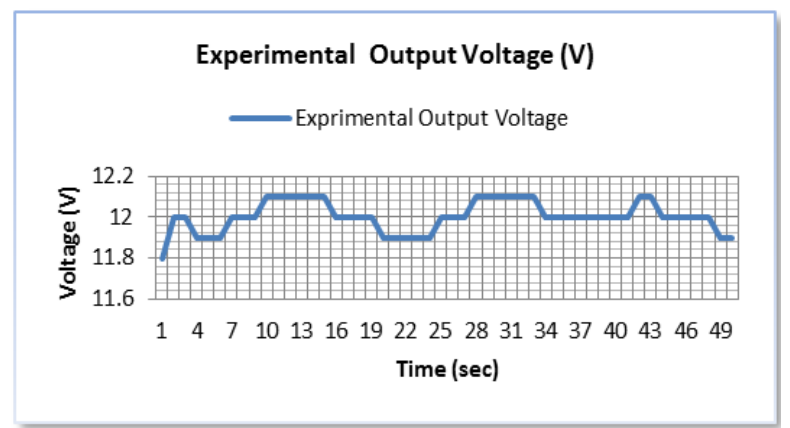

Fig. 7. The instantaneous experimental measured output voltage during the first 50 seconds. 
It is noticed that when output power has value larger than zero, the battery output voltage will be ranging $12 \mathrm{~V}$ to $12.1 \mathrm{~V}$, i.e. it is recharged. When output power equals zero, the battery output voltage will be ranging from $11.8 \mathrm{~V}$ to $11.9 \mathrm{~V}$ because the battery is not charging as shown in Fig. 8 .

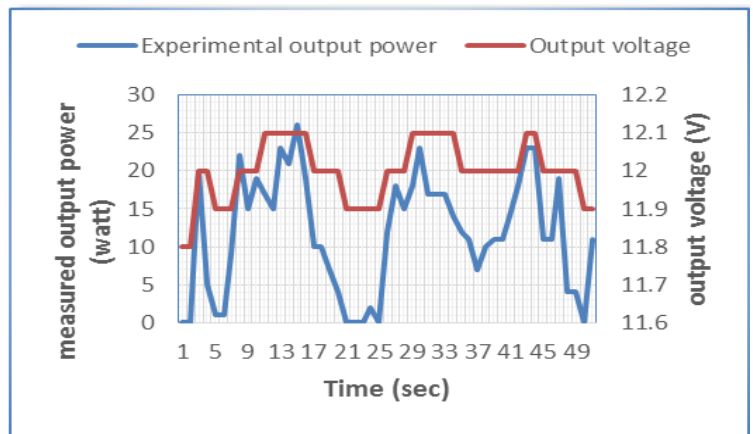

Fig. 8. The instantaneous experimental measured output power and voltage during the first 50 seconds.

\section{Simulation Results}

The instantaneous manufacturer data sheet output power of the wind turbine using the SAM software during the first 50 seconds is shown in Fig. 9.

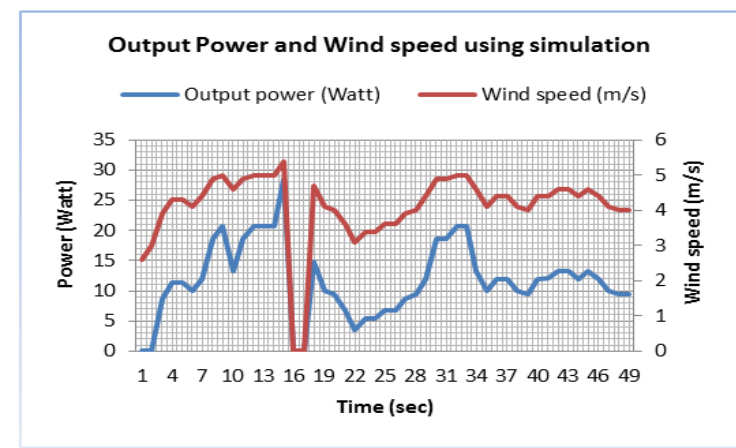

Fig. 9. Output power of the manufacturer, using the SAM software during the first 50 seconds.

\section{COMPARISON BETWEEN EXPERIMENTAL RESULTS, SAM Simulation RESUlts, AND MANUFACTURER DATA SHEET}

The manufacturer data sheet for this module of wind turbine Zephyr Z-501 is drawn the output power in watt versus wind speed in $\mathrm{m} / \mathrm{sec}$ at same wind direction (perpendicular on blade through wind tunnel in indoor test laboratory). The relation is shown in Fig. 10 and Fig. 11 is zooming in curve of data sheet.

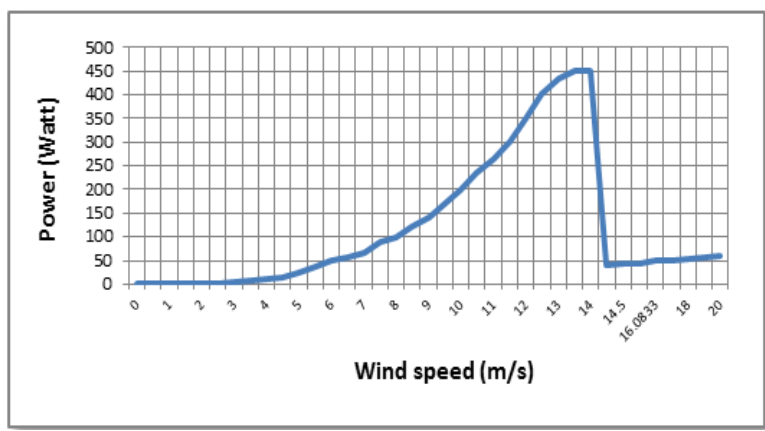

Fig. 10. Data sheet curve from manufacturer, relation between output power and wind speed [9].

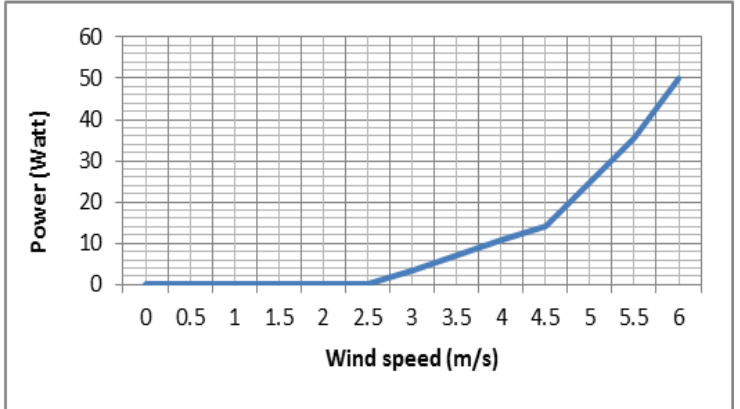

Fig. 11. Data sheet curve from manufacturer, relation between output power and wind speed (zooming in) [9].

When draw the relation of experimental output power reading data versus wind speed reading at this moment as shown in Fig. 12. The output power data is found random values with respect to wind speed values by contrast with the relation in manufacturer data sheet as shown in Fig. 10 and Fig. 11. For example, for higher wind speed value output power was lower one (for $4.3 \mathrm{~m} / \mathrm{sec}$ wind speed out power was 1 watt and for $3 \mathrm{~m} / \mathrm{sec}$ wind speed output power was 20 watt) as shown in Fig. 12.

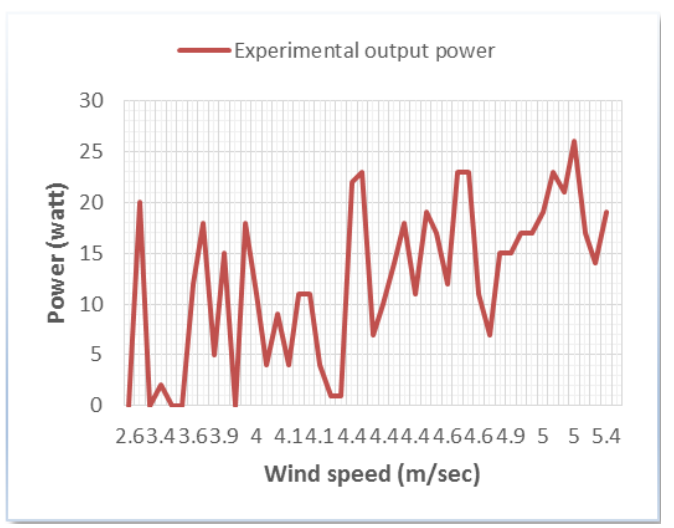

Fig. 12. Experimental measurement relation between output powerand wind speed during the first 50 seconds.

Comparing manufacturer data sheet power and experimental output power, it is noticed that the experimental output power readings are fluctuating around manufacturer datasheet power values as shown in Fig. 13. Manufacturer datasheet power is obtained from applying perpendicular wind speed to wind turbine blade. On the other hand, experimental readings are obtained from variable direction wind speed.

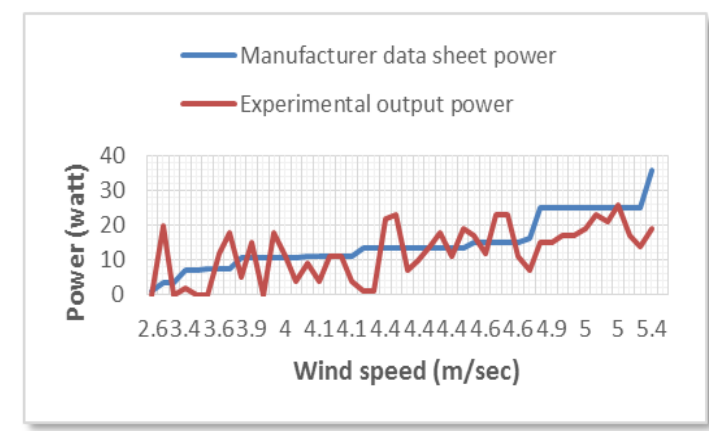

Fig. 13. Comparison between experimental output power readings and manufacturer data sheet power during the first 50 seconds.

A comparison was made between the results obtained from the experimental measurements and the simulation results. 
The results are shown in Fig. 14. Comparing the simulation and experimental results indicates same trend and the real maximum power reached experimentally. But it is less than that calculated by simulation. There was shifting in time of both output readings, there is delaying in reading of experimental output power with respect with the simulated output power. It is clear that it is difficult to rely on the output power of the manufactures data. The simulation program is an effective tool to do real designs.

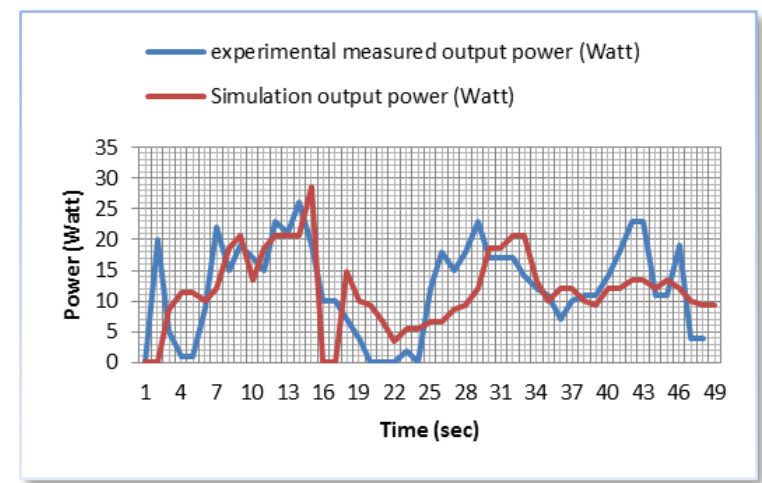

Fig. 14. A comparison was made between the results obtained from the experimental measurements and the SAM simulation.

Correction factor between experimental output power reading and simulated results with SAM program can be calculated by percentage deviation between experimental observed output power and simulated output power from SAM soft package during every wind speed value should be taken into account in simulation programs and design calculations. When percentage deviation is zero, it means that experimental readings and simulation results are the same. Due to mechanical response delay in wind turbine tail movement, positive and negative deviation appears in curve as shown in Fig. 15.

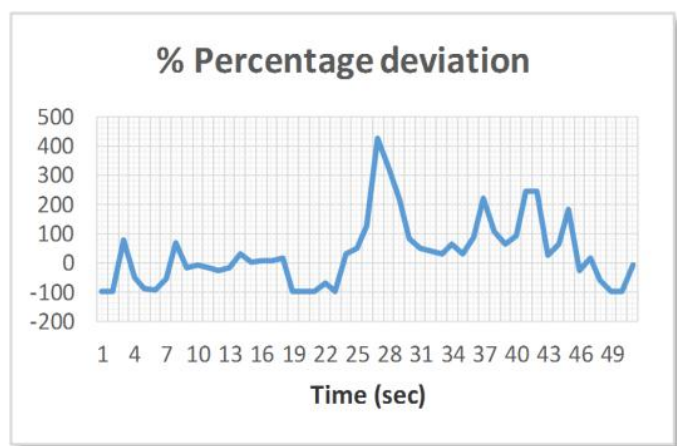

Fig. 15. Percentage deviation between actual output power and simulated output power during every wind speed value.

\section{CONCLUSION AND RECOMMENDATIONS}

The difference between the experimental output readings and the simulation readings is due to the fact that the turbine mechanical response to wind direction variation is too slow. The existing inertia of the wind turbine mechanical control is the reason of, the experimental results are delayed with the simulation results. The blades take sensible time to move to the position where the wind is perpendicular to the blades. Therefore, the outdoor turbine output power is less than the indoor test turbine. This is why, when the wind speed increases, the output wind power increases after few seconds. The fan tail tried to change its direction to match the wind direction. The fan tail's time response was larger than the wind direction change time. The fan tail did not catch the perpendicular wind on the turbine blades. The experimental results are different from that of the turbine manufacturer because the conditions are different, since the wind direction changes instantaneously. It's cleared that manufacturer's data sheet is not reliable to produce certain power at certain speed and it is not suitable for economic evaluation. Therefore, designers are recommended to make their designs based on simulation programs like SAM to reach reasonable results.

Correction factor and percentage deviation should be incorporated into simulation programs and design calculations for multiple values of wind direction. It can be concluded that the used algorithm can help the implementation of the algorithm, which is explained in this thesis to wind turbines and potentially can increase the efficiency of wind power generation.

\section{REFERENCES}

[1] IEEE Canadian Review: Green Power, Mathematical and Computational Applications, December 2007, pp. 10-17.

[2] S. Samanvorakij and P. Kumkratug, "Modeling and simulation PMSG based on wind energy conversion system in Matlab/Simulink," in Proc. the Second Intl. Conf. on Advances in Electronics and Electrical Engineering-AEEE, 2013, pp. 37-41.

[3] M. Ying, G. Li, M. Zhou, and C. Zhao, "Modeling of the wind turbine with a permanent magnet synchronous generator for integration," Power Engineering Society General Meeting IEEE, vol. 3, pp. 1-6, 2007.

[4] Z. Lubosny, Wind Turbine Operation in Electric Power Systems, Berlin, Germany: Springer, 2003.

[5] T. Burton, N. Jenkins, D. Sharpe, and E. Bossanyi, Wind Energy Handbook, 2nd ed. West Sussex, England: John Wiley and Sons publisher, 2001, pp. 320-322.

[6] M. R. Patel, Wind and Solar Power Systems Design, Analysis and Operating, 2nd ed. Broken Sound Parkway, New York: CRC Publisher, 2006, pp. 61-118.

[7] J. F. Manwell, J. G. McGowan, and A. L. Rogers, Wind Energy Explained: Theory, Design and Application, 2nd ed. West Sussex, United Kingdom: John Wiley and Sons Publisher, 2009, pp. 327-375.

[8] System Advisor Model. [Online]. Available: https://sam.nrel.gov/

[9] Harmony World. [Online]. Available: http://harmony-world2000.com/contents/09eco/zephyr/Z-501/Z-501. html

[10] Life in Batteries. [Online]. Available: http://www.lifelinebatteries.com/rvflyer.php?id=2

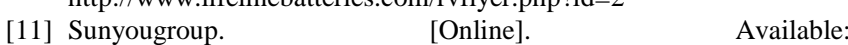
http://www.sunyougroup.com/sunyoulife/furyoku/owlexpressc.htm\#c o

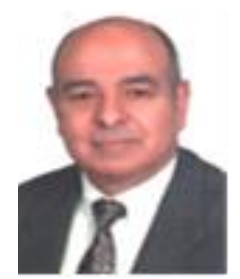

Ahmed Hossam-Eldin got his B.Sc(EE) degree distinction with honors, M.Sc degree from Alexandria University in 1965 and 1969 respectively, and received the Ph.D. degree from Heriot-Watt University, Edinburgh, U.K in 1972, where he worked as a staff member. He joined Alexandria University in 1974 where he was promoted to be a professor of electrical materials and power engineering in 1983 $\mathrm{He}$ is an adjunct professor with the WorldOpen Univ. Oregon, California. He is an authority in his subject. His fields of interest are electromagnetic interference and pollution, cryogenic\& superconducting cables, partial discharges,water treeing and breakdown in dielectrics, distribution systems and their associated problems, renewable energy, biomass and biodiesel, utilization of renewable energy in desalination, cathodicprotection, lightning protection in navy ships and petroleum structures. He has a well-recognized research school. He published more than 300 articles in top refereed journals and published 5 books. He patented some of his works worldwide. He received top national and international awards for his contribution to his society and the achievement to the world. 


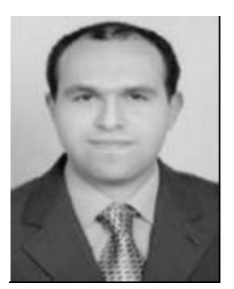

Karim Hassan Youssef was born in Alexandria, Egypt, in 1981. He received the B.Sc., M.Sc., and Ph.D. degrees in electrical engineering from Alexandria University, Alexandria, in 2003, 2005, and 2009 , respectively. He is an assistant professor with the Electrical Engineering Department, Faculty of Engineering, Alexandria University. His current research interests include distribution system design, control and automation, power system control, and renewableenergy. Dr. Youssef was the recipient of the Egyptian Government Award for his Ph.D. dissertation.

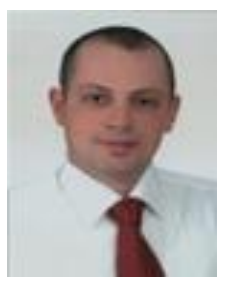

fall of 2015
Kareem Mohamed Ashraf AboRas got his B.Sc(EE) degree distinction with honors in 2010 and M.Sc degree from Alexandria University in 2015 . He is a teacher assistant in the Electrical Engineering Department, Faculty of Engineering, Alexandria University. His fields of interest in renewable energy especially in wind energy. $\mathrm{He}$ is a $\mathrm{PhD}$ student in the Faculty of Engineering, Alexandria University since 